\title{
Вмј Global Health Bridging a false dichotomy in the COVID-19 response: a public health approach to the 'lockdown' debate
}

\author{
Vandana Prasad, ${ }^{1}$ B Subha Sri, ${ }^{2}$ Rakhal Gaitonde (D) ${ }^{3}$
}

To cite: Prasad V, Sri BS, Gaitonde R. Bridging a false dichotomy in the COVID-19 response: a public health approach to the 'lockdown' debate. BMJ Global Health 2020;5:e002909. doi:10.1136/ bmjgh-2020-002909

Handling editor Seye Abimbola

Received 14 May 2020 Accepted 16 May 2020

Check for updates

(c) Author(s) (or their employer(s)) 2020. Re-use permitted under CC BY-NC. No commercial re-use. See rights and permissions. Published by BMJ.

${ }^{1}$ Public Health Resource Network, New Delhi, India ${ }^{2}$ CommonHealth, Thiruvananthapuram, India ${ }^{3}$ Achutha Menon Centre for Health Science Studies, Thiruvananthapuram, India

Correspondence to Dr Rakhal Gaitonde rakhal.gaitonde@sctimst.ac.in

\section{INTRODUCTION}

As the world grapples with the public health emergency brought on by the COVID-19 pandemic, various control strategies have been attempted across the globe resulting in a growing body of evidence. ${ }^{1}$ Thus, we see a wide range of 'lockdowns', from the extremely tight Wuhan style, ${ }^{2}$ to the more measured Rwandan ${ }^{3}$ and more open Swedish model, ${ }^{4}$ and a range of testing protocols ${ }^{56}$ and quarantine durations. ${ }^{78}$ These variations stem from differing interpretations of epidemiology and contextual factors, including the strength of a country's health system, its political orientation and its ability to support citizens, medically and socially, during periods of lockdown. ${ }^{9}$ India stands apart in terms of the stringent application of a national 'lockdown' as its primary and first-line approach to 'flatten the curve' and buy time for health systems preparedness. By 'lockdown', we mean a complete shutting down of all economic activity except those deemed most essential, along with stringent travel bans and stay-at-home orders, with punitive action for any violation.

Predictably, one of the immediate outcomes in India of the lockdown announced with around 4hours' notice was an extreme anxiety among migrants and daily wage earners. ${ }^{10-12}$ With time, their distress has exacerbated, savings depleted and avenues for loans exhausted. ${ }^{13}$ This crisis has been heartrendingly symbolised by images of migrants setting off home to cover thousands of kilometres on foot, several dying along the way. ${ }^{14}{ }^{15}$ Government's responses for relief have been only as good as the system's ability to reach the most vulnerable. Thus, the poor and destitute across the country are at the brink of hunger and starvation, ${ }^{16} 17$ while the economy plummets, leading to continuing discussions about the 'trade-off' between economics and public health, between saving

\section{Summary box}

The current approach to assessing risks and defining interventions in the COVID-19 pandemic takes a narrow medical/epidemiological view.

- A false dichotomy between saving lives and saving livelihoods has dominated the decision-making on responses to the pandemic.

- A comprehensive public health approach is needed that would address social determinants and medical requirements simultaneously, with equity as an overarching principle.

- A framework, including the major elements of COVID-19-related factors, health systems preparedness, non-COVID-19 medical conditions, social determinants and social protection, is proposed, with an illustration of its practical application.

- By taking the lived reality of the poor and marginalised into account, this framework provides communities with more agency than one-size-fits-all approaches to COVID-19 control.

lives or saving livelihoods. Such a trade-off is clearly belied by the fact that of a total number of 515 recorded deaths associated with the COVID-19 pandemic in India by 12th April, 334 were deaths directly from COVID-19 while 181 were distress deaths. ${ }^{15}$ Thus, from an equity lens, the dichotomy between livelihoods and lives seems false, with both COVID-19 and the loss of livelihoods leading to dire consequences on morbidity and mortality.

There is also a significant lack of accommodation of the issues of non-COVID-19-related medical emergencies in the implementation of the lockdown. ${ }^{18}$ There have been many anecdotal reports about deaths due to denial of or delays in healthcare, including maternal mortalities. ${ }^{19-21}$ Inability to access emergency care for deliveries, chemotherapy and dialysis, and lack of availability of blood for lifethreatening medical and surgical emergencies have also been widely reported. ${ }^{22}$ National 


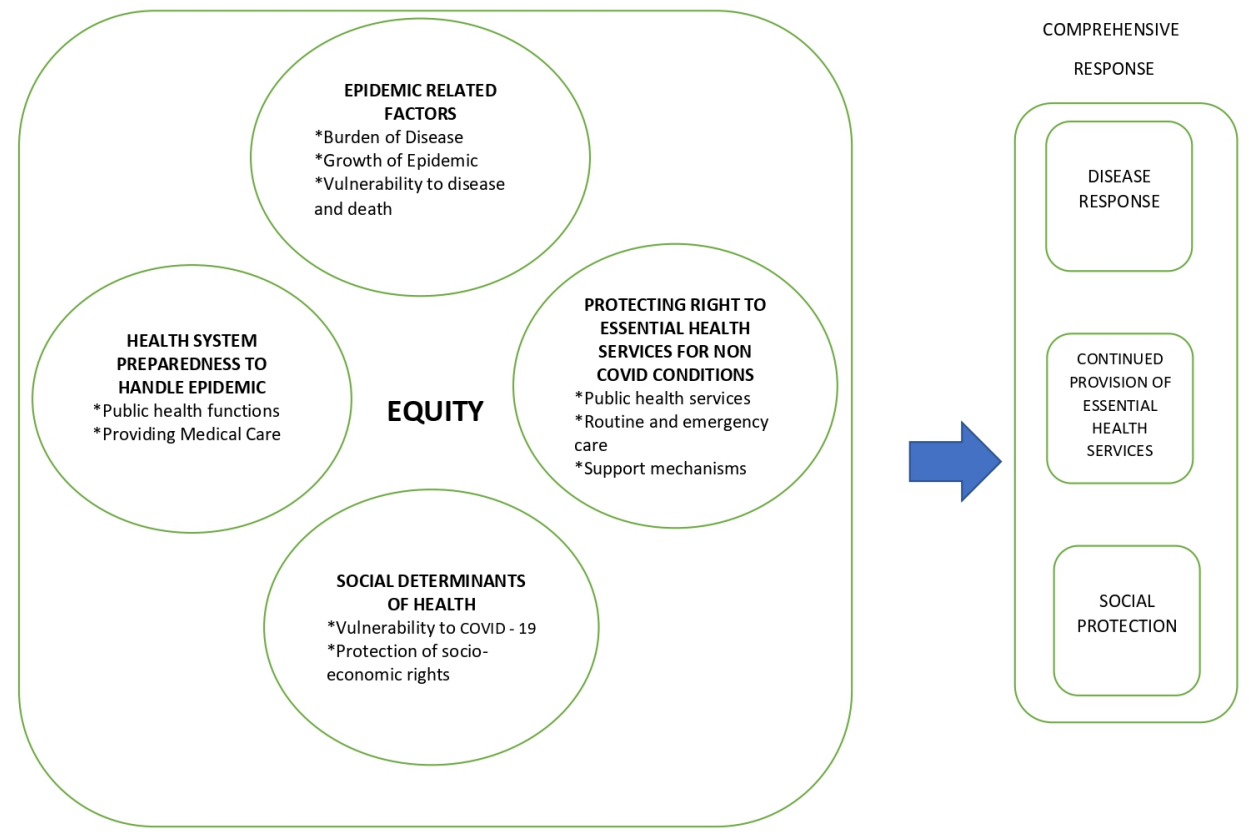

Figure 1 A public health framework for COVID-19.

Health Mission data suggest an alarming 53\% and 30\% decrease, respectively, in the numbers of eclampsia and acute cardiac emergencies handled in March compared with the previous month. ${ }^{23}$ These are not indirect, but direct consequences of the COVID-19 control measures. However, while daily updates make COVID-19-related data public, data on other health issues are not being collated or used to moderate response.

The authors contend that this dichotomy between the crisis caused by the disease and that caused by the responses to it demonstrates the hegemony of the 'medical' over the 'social', and is symptomatic of the blind-spotting in policy to health and social inequity. Thus, we argue for a public health framework that necessarily treats the social determinants of health (SDH) and health equity in the same frame as the epidemiological/ medical, for the evaluation of risks and interventions in a COVID-19-like pandemic, rather than treating predictable socioeconomic consequences with dire short-term morbidity and mortality outcomes as 'collateral damage'.

\section{A PROPOSED FRAMEWORK}

We present a framework (figure 1) deriving from the above principles that could be used to define the scope and scale of the crisis, as well as plan a response to it. Further on, we suggest a few indicators to measure each of these while operationalising this framework in specific situations.

\section{Epidemic-related factors}

Currently, responses to the epidemic in India are based only on measures of the burden of COVID-19 in a specific area and the growth of the epidemic. ${ }^{24} \mathrm{~A}$ public health approach would also consider other aspects of the situation like vulnerability to mortality due to COVID, risk of disease outbreaks, and local contextual factors. Indicators to measure each of these aspects need to be collected at local levels and monitored in real time.

\section{Health systems preparedness to handle the COVID epidemic}

In addition to the COVID disease-related considerations listed above, health systems capacity to address the COVID epidemic needs to be factored in at two levels:

a. Preparedness for basic public health functions: COVID-19-related screening, contact tracing and quarantining, and strengthening disease surveillance systems.

b. Providing medical care: for mild and severe disease, and deployment of the private sector for the same.

While health systems preparedness is an important consideration in the planning of any response, we caution that this should include a realistic assessment of the short-term capacity to achieve such preparedness. Indicators such as ability to further increase human resources and add intensive care unit beds, and whether COVIDrelated training for all health staff has been completed, could be used. If the health system in a particular area has already achieved its maximum capacity of preparedness, and there is little potential to further optimise it in the short term, continuing lockdowns indefinitely offers no tangible health systems advantage; rather, the socioeconomic costs would far outweigh any benefits. In this situation, a more realistic slew of interventions that focus on protection of the vulnerable from infection and minimising deaths should be the way forward.

\section{Protecting the right to essential health services for non- COVID-19 medical conditions}

WHO emphasises that essential health services should continue as a means of maintaining public trust even 
as health systems grapple with COVID. ${ }^{1}$ Thus, the health system's ability to continue providing essential health services is a key consideration, including services for pregnancy and other reproductive healthcare, emergency surgeries, communicable diseases like tuberculosis, and timedependent medical treatment like cancer chemotherapy and dialysis. Key national programmes, as for immunisation, reproductive health and tuberculosis control, need to continue. Indicators that are used in normal times to assess these programmes should be collected without interruption and monitored as usual. Projections of the need for institutional delivery, routine immunisation, chemotherapy, dialysis, blood donation and availability of essential drugs need to be factored into any district-level plan as part of a pandemic response. Additional data also need to be collected with respect to delays or denials of healthcare.

The continuation of essential health services is also dependent on several support mechanisms including availability of transport for patients and healthcare workers, and maintenance of production and supply chains of medical equipment and drugs. Indicators to assess such administrative support for these allied processes need to be built into the assessment plan.

\section{Social determinants of health}

We suggest that the consideration of SDH in the present crisis be done at two levels.

\section{Social determinants and vulnerability to COVID}

The socioeconomic determinants of communities such as housing, livelihood, food security and access to information determine the ability to follow and adhere to public health advice regarding control measures. In their absence, measures such as stay-at-home orders in the lockdown can prove counterproductive. Social determinants like nutrition are also contributors to comorbidities like hypertension and diabetes that add to the vulnerability of those infected. Thus, the urban poor, for example, face a triple burden of hunger and starvation, being vulnerable to severe disease because of high prevalence of comorbidities, ${ }^{25}$ while simultaneously being unable to practise any of the suggested control measures because of lack of housing and water. These need to be key considerations in the planning of a public health response to the current crisis.

\section{Protection of socioeconomic rights}

The current stringent lockdown has compromised the already fragile status of the vulnerable by denying them livelihoods and food security. Thus, it is important to include social protection measures in the framework to ensure that the SDH are accessible to everyone, both to prevent the infection and to mitigate the effects of COVID control measures themselves.

\section{Equity}

We propose equity as an overarching principle for each of the above considerations. The current response of a universal lockdown bears starkly differential effects based on class, religion, caste and gender and their intersectionalities. ${ }^{12}$ We emphasise that any measure to address the current crisis must consider its differential effects on vulnerable groups such as the homeless, urban slum dwellers, persons in prisons and other institutions, survivors of domestic violence and proactively take steps to address any equity gaps. This would entail mapping of different vulnerable groups in each geographical area, collection of disaggregated data and specific components for vulnerable persons/households/communities in each and every action plan.

In table 1, we illustrate application of the framework to define the scope of the problem and suggest indicators to measure progress, using the example of an urban slum with a COVID outbreak in a city reporting a high number of cases and deaths.

Such an analysis facilitates nuanced responses. In this situation, there may be justification for restricting entry into or out of the community. However, deaths could be minimised by identifying and enabling individuals with known comorbidities to practise physical distancing through proximal-to-community institutional quarantining. This can be combined with a protocol for early hospitalisation of those with comorbidities with dedicated ambulance facilities. Essential health services could be continued by identifying hospitals (both private and public) that will provide non-COVID-related emergency and semi-emergency care without charges. Urban health posts need to be set up to continue routine immunisation and antenatal care with adequate physical distancing. Arrangement of community kitchens and dry rations distribution, and adequate supply of water and public handwashing stations should be core parts of any plan. Applying an equity lens, civil society organisations and community volunteers could help identify vulnerable groups, households and individuals, and provide special attention and tailor-made responses. Setting up of special helplines for the vulnerable is another feasible option.

The framework could be similarly applied to other situations with a nuanced analysis leading to contextualised responses.

\section{CONCLUSIONS}

The term 'lockdown' has gatecrashed into our vocabulary and imaginations, and its all-encompassing militaristic scope seems to crowd out a diversity of contexts, locations and vulnerabilities. Its stringent implementation by local administrations through 'curfews' and 'sealings' has converted a lockdown that was initially premised on a public health logic into one with a significant law-andorder component.

In the last few weeks, a number of voices have cautioned against a one-size-fits-all lockdown, calling instead for the recognition of contextual diversity while designing response strategies. ${ }^{26}$ The WHO supports the argument for approaches that go beyond disease-centric 
Table 1 Application of the framework in a situation of an urban slum with a COVID outbreak in a city reporting high number of COVID-19 cases

\begin{tabular}{|c|c|c|}
\hline Domains to be considered & Defining the problem & Suggested indicators \\
\hline COVID epidemic-related factors & $\begin{array}{l}\text { High burden of COVID-19 cases } \\
\text { Rapid progression of the epidemic } \\
\text { Vulnerability to COVID-19 mortality among adults } \\
\text { with multiple comorbidities } \\
\text { Presence of good health infrastructure } \\
\text { Presence of civil society groups that can support } \\
\text { response }\end{array}$ & $\begin{array}{l}\text { Total number of cases of COVID-19 } \\
\text { Total number of COVID- } 19 \text { deaths } \\
\text { Doubling time of cases and deaths } \\
\text { Proportion of population over } 60 \text { years } \\
\text { Proportion of population with hypertension, } \\
\text { diabetes, obesity, malnutrition }\end{array}$ \\
\hline Social determinants of health & $\begin{array}{l}\text { Inability to adhere to public health advice } \\
\text { regarding control measures due to overcrowding } \\
\text { and cramped living spaces, common toilets } \\
\text { Extremely vulnerable to economic effects of } \\
\text { lockdowns due to precarious work }\end{array}$ & $\begin{array}{l}\text { Average number of people in a single household } \\
\text { Sq feet living space per person } \\
\text { Number with access to water and soap } \\
\text { Unemployment rate } \\
\text { Percentage coverage with food and social } \\
\text { sumber schemes } \\
\text { Proportion of BPL households provided } \\
\text { economic support and food } \\
\text { Proportion of ICDS and school enrolled children } \\
\text { provided dry rations or food at home } \\
\text { Proportion of migrants housed in camps and } \\
\text { receiving food and healthcare }\end{array}$ \\
\hline Overarching equity considerations & $\begin{array}{l}\text { Mapping of population groups with special } \\
\text { vulnerabilities and special needs }\end{array}$ & $\begin{array}{l}\% \text { coverage of persons with disability* } \\
\% \text { coverage of homeless population* } \\
\% \text { coverage of persons in institutions }\end{array}$ \\
\hline
\end{tabular}

*With respect to all dimensions listed above.

ATT, Anti-Tuberculosis Treatment

; BPL, Below Poverty Line

; ICDS, Integrated Child Development Scheme

; NCD, Non-Communicable Diseases

; PPE, personal protective equipment .

thinking and acknowledges socioeconomic 'benefit' as one of the factors that need to be taken into account, calling for an acknowledgement of a trade-off between public health measures and the basic needs of the people. It also clearly mentions that movement restriction measures are blunt tools 'with considerable social and economic costs' that 'should be implemented with the understanding, consent and participation of communities, and based on the principle of doing no harm'. ${ }^{1}$ In India, Kerala's Abraham Committee report on post-lockdown planning cautions that the 'cure could be more expensive than the disease' and calls for a graded approach to tackling the epidemic. ${ }^{27}$ Increasingly, there is recognition in Africa that lockdowns may not be the solution in contexts of poverty and inequity, arguing instead for the development of communitybased strategies that learn from the HIV responses that were led by social movements. ${ }^{28}$ However, the above examples persist with the false dichotomy by juxtaposing economic activity against epidemiological risk, rather than acknowledging socioeconomically determined risk alongside epidemiological risk.

We present a comprehensive framework and an indicative operationalisation that highlight how to plan a 
response, taking into account human rights, health systems and the SDH. This also provides communities greater agency than a one-size-fits-all 'lockdown'. We hope that this framework will spark discussion and contribute to a more humane and better public health response to the pandemic.

Twitter Rakhal Gaitonde @rakhalgaitonde

Acknowledgements The authors acknowledge the rich discussions on COVID-19 within Jan Swasthya Abhiyan (People's Health Movement, India) and in its e-group, and within the Kerala State Expert Committee on COVID-19.

Contributors All authors contributed to the conceptualisation, drafting, revising and finalisation of the manuscript.

Funding The authors have not declared a specific grant for this research from any funding agency in the public, commercial or not-for-profit sectors.

Competing interests None declared.

Patient consent for publication Not required.

Provenance and peer review Not commissioned; internally peer reviewed.

Data availability statement There are no data in this work.

Open access This is an open access article distributed in accordance with the Creative Commons Attribution Non Commercial (CC BY-NC 4.0) license, which permits others to distribute, remix, adapt, build upon this work non-commercially, and license their derivative works on different terms, provided the original work is properly cited, appropriate credit is given, any changes made indicated, and the use is non-commercial. See: http://creativecommons.org/licenses/by-nc/4.0/.

ORCID iD

Rakhal Gaitonde http://orcid.org/0000-0003-4046-8380

\section{REFERENCES}

1 World Health Organization. COVID-19 strategy update. Geneva: World Health Organization, 2020.

2 Aylward B, Liang W. Report of the WHO-China Joint Mission on Coronavirus Disease 2019 (COVID-19) [Internet], 2020. Available: https://www.who.int/docs/default-source/coronaviruse/who-chinajoint-mission-on-covid-19-final-report.pdf

3 Bizoza A, Sibomana S. Indicative socio-economic impacts of the novel coronavirus (Covid-19) outbreak in eastern Africa: case of Rwanda, 2020.

4 Paterlini M. 'Closing borders is ridiculous': the epidemiologist behind Sweden's controversial coronavirus strategy. Nature 2020;580:574.

5 Indian Council of Medical Research. Strategy for COVID-19 testing in India (version 4, dated, 09/04/2020). New Delhi, 2020.

6 Beaumont P. Coronavirus testing: how some countries got ahead of the rest. The Guardian [Internet], 2020. Available: https://www. theguardian.com/world/2020/apr/02/coronavirus-testing-how-somecountries-germany-south-korea-got-ahead-of-the-rest

7 Public Health England. Stay at home: guidance for households with possible coronavirus (COVID-19) infection [Internet]. Available: https://www.gov.uk/government/publications/covid-19-stay-athome-guidance/stay-at-home-guidance-for-households-withpossible-coronavirus-covid-19-infection [Accessed 3 May 2020].

8 Health \& Family Welfare Department Government of Kerala. Revised guidelines for testing, quarantine, hospital admission and discharge for COVID-19 based on current risk assessment [Internet], 2020. Available: https://dhs.kerala.gov.in/wp-content/uploads/2020/03/ reg 12032020.pdf [Accessed 3 May 2020].

9 Hale T, Petherick A, Phillips T, et al. Variation in government responses to COVID-19. Blavatnik school of government working paper. 31, 2020.
10 UN News. India: Migrant workers' plight prompts UN call for 'domestic solidarity' in coronavirus battle [Internet], 2020. Available: https://news.un.org/en/story/2020/04/1060922

11 Khera R. Covid-19: What can be done immediately to help vulnerable population. Ideas for India [Internet], 2020. Available: https://www.ideasforindia.in/topics/poverty-inequality/covid-19what-can-be-done-immediately-to-help-vulnerable-population.html

12 Mander H. A pandemic in an unequal India. The Hindu, 2020. Available: https://www.thehindu.com/opinion/op-ed/a-pandemic-inan-unequal-india/article31221919.ece

13 The Hindu. Data | $96 \%$ migrant workers did not get rations from the government, $90 \%$ did not receive wages during lockdown: survey [Internet], 2020. Available: https://www.thehindu.com/data/data-96migrant-workers-did-not-get-rations-from-the-government-90-didnot-receive-wages-during-lockdown-survey/article31384413.ece

14 Slater J, Masih N. In India, the world's biggest lockdown has forced migrants to walk hundreds of miles home. The Washington Post [Internet], 2020. Available: https://www.washingtonpost.com/world/ asia_pacific/india-coronavirus-lockdown-migrant-workers/2020/03/ 27/a62df166-6f7d-11ea-a156-0048b62cdb51_story.html

15 Rawal V, Manickem KA, Rawal V. Are Distress Deaths Necessary Collateral Damage of Covid-19 Response? [Internet]. Ideas. Available: http://www.networkideas.org/featured-themes/2020/04/ are-distress-deaths-necessary-collateral-damage-of-COVID-19response-the-experience-of-first-three-weeks-of-the-lockdown-inindia/ [Accessed 3 May 2020].

16 Steering Committee Right to Food Campaign. RTFC statement on "No More Lockdown", 2020.

17 Pandit A. 50\% of rural India is eating less due to lockdown: Survey. The Times of India [Internet], 2020. Available: https://timesofindia. indiatimes.com/india/nearly-half-of-rural-households-eating-feweritems-less-number-of-times-to-overcome-covid-crisis-survey/ articleshow/75703178.cms

18 Dore B. Covid-19: collateral damage of lockdown in India. BMJ 2020;369:m1711.

19 SAMA Resource group for women and health. Access to Maternal health care: Challenges with lockdown [Internet], 2020. Available: http://www.samawomenshealth.in/access-to-maternal-health-carechallenges-with-lockdown/ [Accessed 3 May 2020]

20 Shrivastava S, Sivakami M. Obstetric Violence During COVID-19 Is yet Another Challenge for Indian Women. The Wire [Internet], 2020. Available: https://thewire.in/rights/women-covid-19-obstetricviolence

21 The Times of India. Hospitals can't insist on coronavirus test before treatment, says govt. [Internet], 2020. Available: https://timesofindia. indiatimes.com/india/hospitals-cant-insist-on-covid-test-beforetreatment-govt/articleshow/75438835.cms

22 Salve P. COVID-19 Lockdown Causing Further Shortage At Blood Banks. IndiaSpend [Internet], 2020. Available: https://www. indiaspend.com/covid-19-lockdown-causing-further-shortage-atblood-banks/

23 Rukmini S. How covid-19 response disrupted health services in rural India. livemint [Internet], 2020. Available: https://www.livemint.com/ news/india/how-covid-19-response-disrupted-health-services-inrural-india-11587713155817.html

24 Government of India. Order of Ministry of Home Affair [Internet], 2020. Available: https://www.mha.gov.in/sites/default/files/MHA Order Dt. 1.5.2020 to extend Lockdown period for 2 weeks w.e.f. 4.5.2020 with new guidelines.pdf [Accessed 1 May 2020].

25 Bhojani U, Beerenahalli TS, Devadasan R, et al. No longer diseases of the wealthy: prevalence and health-seeking for self-reported chronic conditions among urban poor in southern India. BMC Health Serv Res 2013;13:306.

26 Douglas M, Katikireddi SV, Taulbut M, et al. Mitigating the wider health effects of covid-19 pandemic response. BMJ 2020;369:m1557.

27 Government of Kerala. Report of the expert Committee on strategy for easing lockdown restrictions. Thiruvananthapuram; 2020.

28 Du Toit A. COVID-19 responses in Africa: Ok, one size doesn't fit all. Now what? African Arguments. [Internet], 2020. Available: https:// africanarguments.org/2020/04/28/covid-19-responses-in-africa-okone-size-doesnt-fit-all-now-what/ [Accessed 3 May 2020]. 